\title{
NOTE
}

\section{Lanthanide tetrad effect observed in marine environment}

\author{
AKIMASa MaSuda and Yoshiniro IKeUCHI \\ Department of Earth Sciences, Kobe University, Nada, Kobe 657, Japan
}

(Received November 14, 1978)

\begin{abstract}
We have found that lanthanide tetrad effect (PEPPARD et al., 1969) is operative for heavy rare-earth elements (REE) in a phosphorite sample (GOLDBERG et al., 1963). Also it has been evinced that the similar effect is observed for REE in sea waters. However, in the case where the plot (Masuda-Coryell plot) is void of the points for $\mathrm{Tb}$, Ho and $\mathrm{Tm}$, the resultant joint-line pattern is to have the common characteristics that the zigzag pattern is pointed downward at $\mathrm{Dy}$ and $\mathrm{Yb}$ and upward at Er. That is, the zigzag pattern with phase coincidence in breaking and its direction is a partially cut-off reflection of lanthanide tetrad effect.

Employing the stable isotope dilution technique, we could determine REE in one-liter sample of sea water, with errors less than $2 \sim 3 \%$.
\end{abstract}

\section{INTRODUCTION}

In studies of liquid-liquid (aqueous-benzene) extraction involving $\mathrm{H}[\mathrm{DOP}]$, di n-octyl phosphinic acid, $\left(\mathrm{n}-\mathrm{C}_{8} \mathrm{H}_{17}\right)_{2} \mathrm{PO}(\mathrm{OH})$ and $\mathrm{DEH}[\mathrm{ClMP}]$, di 2-ethyl hexyl chloromethyl phosphonate, $\left(\mathrm{ClCH}_{2}\right) \mathrm{PO}\left(\mathrm{OC}_{6} \mathrm{H}_{12} \cdot \mathrm{C}_{2} \mathrm{H}_{5}\right)_{2}$, PEPPARD et al. (1969) recognized tetrad effect on lanthanides (III). According to their observation, when the concentration ratios between the aqueous phase and the organic phase is plotted on semi-logarithmic diagram against the atomic number of the lanthanide, the plot consists of four separate curves, encompassing four points, La-Ce-Pr-Nd, Pm-Sm-Eu-Gd, Gd-Tb-Dy-Ho and Er-Tm-Yb-Lu, with $\mathrm{Gd}$ being an element common to the second and the third tetrad. The results for one of two systems investigated by them are cited in Fig. 1.

The above authors suggested that the first, second and third cusps correspond to "onequarter-filled", "half-filled" and "three-quartersfilled" shell effects, respectively. That is, three discontinuities occur respectively between the third and the fourth, just at the seventh, and between the tenth and eleventh $4 f$ electron filling. (As is well known, the maximum number for $4 f$ electron orbitals is fourteen, and it was theoretically argued that a discontinuity in properties should occur at Gd, because of a predicted half-filled shell effect.)

NUGENT (1970) advanced an explanation that the tetrad effect in question originates mainly from the quantum mechanical interelectronic repulsion energy of the $q$ electrons in $4 f^{q}$ electronic configuration. The tetrad effect is observed in the changes of the unit cell volumes, the standard free energy of complex formation (SIEKIERSKI, 1971; SIEKIERSKI and FIDELIS, 1972) and free enthalpy of hydration (Guillaumont and David, 1974).

Well it is an interesting problem whether the lanthanide tetrad effect can be observed in nature. As mentioned below, we have noticed that the effect under consideration is found in materials associated with marine environment.

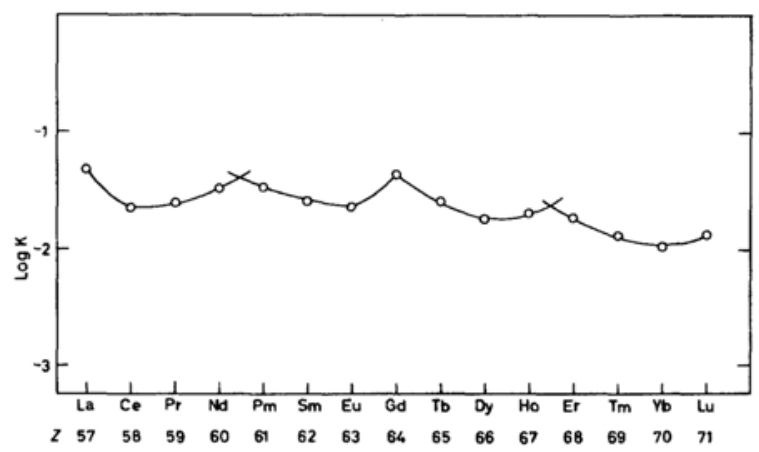

Fig. 1. Example of the tetrad effect (PEPPARD et al., 1969). Variation of $\log K$ with atomic number $Z$ where $K$ is the equilibrium distribution constant between an aqueous solution of $1.1 \mathrm{~F} \mathrm{LiBr}+0.5 \mathrm{~F} \mathrm{HBr}$ and the solution of $0.6 F$ di(2-ethylhexyl) chloromethyl phosphonate in benzene, at $22^{\circ} \pm 2^{\circ} \mathrm{C}$. 


\section{Examination of Data by Goldberg $e t$ al.}

GoldBERG et al. (1963) analyzed a surface sea water, a phosphorite and a manganese nodule for rare-earth elements, REE, i.e., lanthanides, employing the technique of neutron activation analysis. According to their description, the data on phosphorite is of highest quality, good to about $\pm 3 \%$. It is understood (GoldBERG et al., 1963) that the REE found in the oceanic phosphorite are very probably precipitated directly from sea water. It grasps and retains our attention that, as seen in Fig. 2, the phosphorite REE determined with best accuracies exhibit two arcuate curves comprising two tetrads, Gd-Tb-Dy-Ho and Er-Tm-Yb-Lu. (For normalization, REE abundances in Leedey chondrite (MASUdA et al., 1973; MASUDA, 1975) are employed in this paper.) It is of great significance that these two tetrads are in complete agreement with the third and fourth tetrads pointed out by PEPPARD et al. (1969). However, it is hard to recognize tetrad effect on REE lighter than Gd.

Chondrite-normalized REE pattern for a surface sea water from 100 meter depth, $15 \mathrm{~km}$ west of San Diego, is shown in Fig. 3. It is less easy to discern tetrad effects in Fig. 3 than in Fig. 2. But, since Tm determination is subject to relatively great uncertainties, little attention may be paid to $\mathrm{Tm}$ in drawing a smooth curve. Thus it can be said that the same tetrad effect as observed in phosphorite (Fig. 2) is found also in sea water (Fig. 3). It is noted here that if the abundance data are available for Gd, Dy,

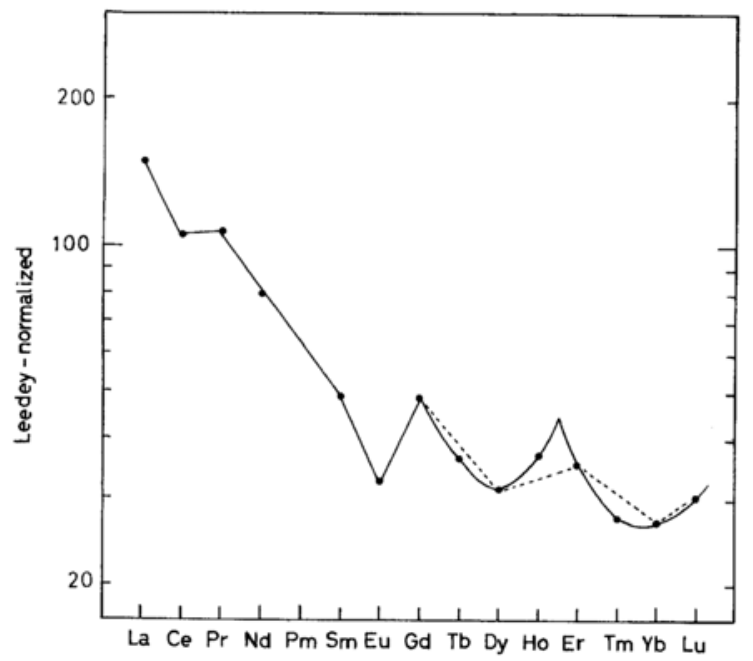

Fig. 2. Chondrite-normalized REE pattern of a phosphorite investigated by GOLDBERG et al. (1963).

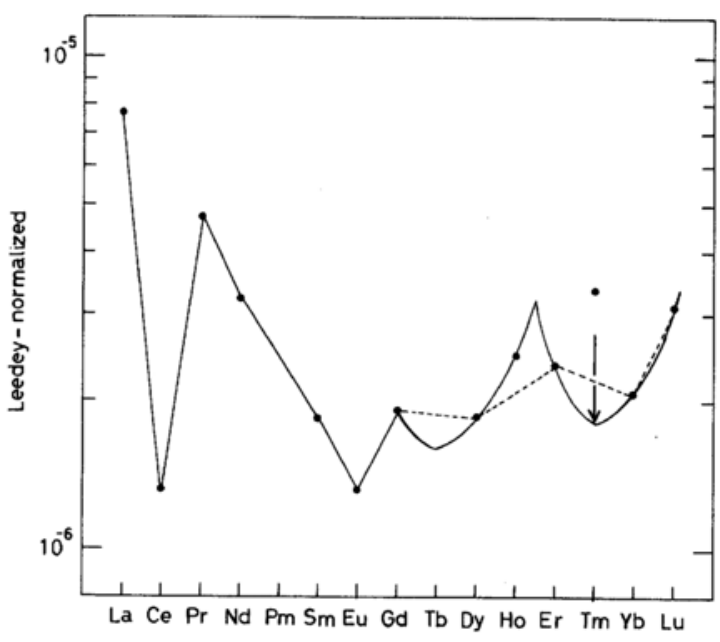

Fig. 3. Chondrite-normalized REE pattern of a sea water sample, $15 \mathrm{~km}$ west of San Diego, investigated by GOLDBERG et al. (1963).

$\mathrm{Er}, \mathrm{Yb}$ and $\mathrm{Lu}$ and the points for these elements are connected by straight lines, apparently zigzag patterns as indicated by broken lines in Figs. 2 and 3 will be obtained. Those zigzag patterns should have common features that they are pointed downward at Dy and $Y b$ and upward at Er. Emphasis must be placed on that apparently zigzag patterns shown by broken lines in Figs. 2 and 3 are reflection of tetrad effect shown by smooth solid lines. This must borne in mind, because it is impossible for usual stableisotope dilution technique to determine monoisotopic REE such as $\mathrm{Tb}$, Ho and $\mathrm{Tm}$.

\section{Determination of REE in SEa Water}

To check the ubiquity of tetrad effect on heavy REE in sea water, we have determined $\mathrm{REE}$ in sea water from 1,690 meter depth in Pacific Ocean $32^{\circ} 28^{\prime} \mathrm{N}, 138^{\circ} 49^{\prime} \mathrm{E}$. As mentioned above, since $\mathrm{Tb}$, Ho and Tm cannot be determined by mass spectrometric stable isotope dilution technique, our criterion for the examination of tetrad effect under consideration is based on zigzag pattern with phase coincidence in positions of up-and-down pointings.

GOLDBERG et al. (1963) and HoGDAHL et al. (1968) used a 10 liter sea water sample for each of their determinations of REE, but we succeeded in determination of REE using a oneliter sample, with errors of $2 \sim 3 \%$, in which stable isotope dilution was employed; both GoldBerg et al. and HфGDAHL et al. employed neutron activation. 
Table 1. REE concentrations (ppt) in seawater sample from $1,690-m$ depth, $32^{\circ} 28^{\prime} \mathrm{N}, 138^{\circ} 49^{\prime} \mathrm{E}$

\begin{tabular}{lcllll}
\hline \hline $\mathrm{La}$ & 5.09 & $\mathrm{Eu}$ & 0.156 & $\mathrm{Er}$ & 0.974 \\
$\mathrm{Ce}$ & 2.84 & $\mathrm{Gd}$ & 0.908 & $\mathrm{Tm}$ & $0: 131^{*}$ \\
$\mathrm{Pr}$ & - & $\mathrm{Tb}$ & $0.147^{*}$ & $\mathrm{Yb}$ & 0.935 \\
$\mathrm{Nd}$ & 3.53 & $\mathrm{Dy}$ & 0.984 & $\mathrm{Lu}$ & 0.165 \\
$\mathrm{Sm}$ & 0.658 & Ho & $0.306^{*}$ & & \\
\hline
\end{tabular}

* Estimated from Fig. 5.

A sample of about one-liter was acidified by $3 \sim 4 \mathrm{ml}$ of $6 \mathrm{~N} \mathrm{HCl}$ to be stored. In separation of REE, about $20 \mathrm{mg}$ of purified $\mathrm{Fe}$ in solution were added together with REE spike solution, then $2 \mathrm{ml}$ of concentrated $\mathrm{NH}_{4} \mathrm{OH}$ was added to co-precipitate REE with $\mathrm{Fe}(\mathrm{OH})_{3}$ at $\mathrm{pH}=10 \sim 11$. After hydroxides were centrifuged, they were dissolved by $3 \mathrm{ml}$ of $0.5 \mathrm{~N}$ $\mathrm{HCl}$. REE fraction was separated by cationexchange column $(8 \mathrm{~mm} \times 50 \mathrm{~mm})$. Impurities of REE in reagents used were subtracted.

Our results are presented in Table 1 and the corresponding chondrite-normalized REE pattern is shown in Fig. 4. Like sea water analyzed by GoldBerg et al. (1963), our sample shows large negative $\mathrm{Ce}$ anomaly. Compared with the value $\mathrm{Ce}^{*}$ estimated to fall on the $\mathrm{La}-\mathrm{Nd}$ join, the depletion factor for the observed $\mathrm{Ce}$ value is $3.34\left(=\mathrm{Ce}^{*} / \mathrm{Ce}\right)$. The corresponding factor for the sample studied by GOLDBERG et al. is 4.35 .

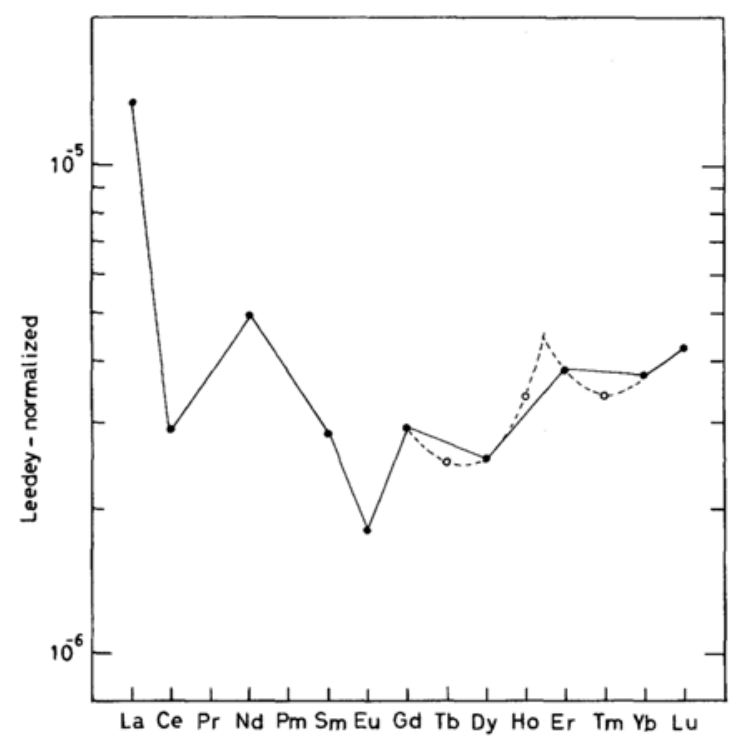

Fig. 4. Chondrite-normalized REE pattern of sea water, from 1,690-m depth, $32^{\circ} 28^{\prime} N, 138^{\circ} 49^{\prime} E$, analyzed by us. Open circles refer to values estimated from Fig. 5 .

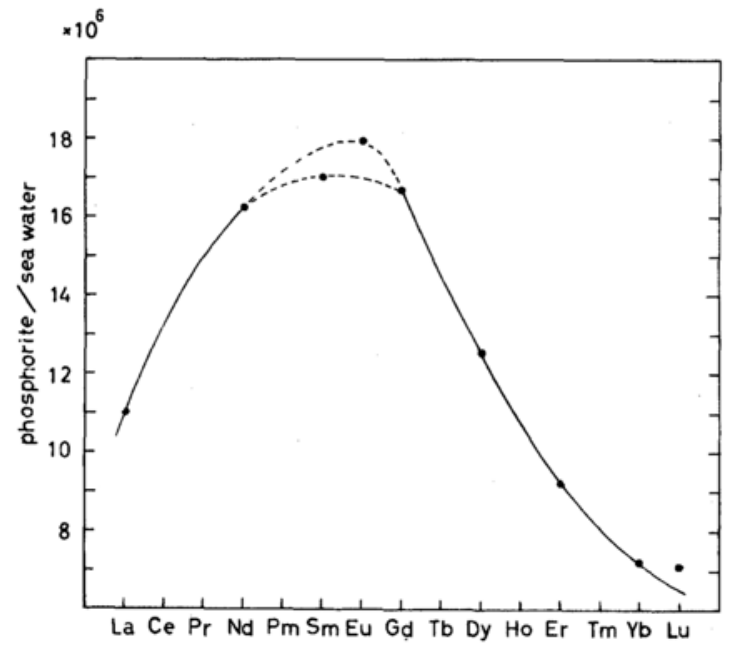

Fig. 5. Concentration ratios of a phosphorite (GoLD. BERG et al., 1963) to our sea water sample (cf. Table 1).

Our deepest attention is engaged to the zigzag phase coincidence of our sea water pattern (Fig. 4) with the patterns shown by broken lines in Figs. 2 and 3. It can be said that the zigzag pattern for heavy REE is ubiquitous with common up-and-down effect and that this effect is essentially an interrupted reflection of lanthanide tetrad effect on heavy REE.

Effectively close relationship between phosphorite (GolDBERG et al., 1963) and our sea water is shown in Fig. 5. Based on this relationship, we can estimate the concentrations of $\mathrm{Tb}, \mathrm{Ho}$ and $\mathrm{Tm}$ for our sample; estimated values are presented in Table 1. Open circles in Fig. 4 represent the estimated values for $\mathrm{Tb}$, Ho and $\mathrm{Tm}$, and curves drawn with broken line display the presumed tetrad effect.

\section{DiscusSION}

It has been evinced that there is a tetrad effect operative for heavy REE in marine environment. As pointed out above, it is hard to recognize the similar effect on light REE. It is true that the situation is complicated by the natural absence of Pm and the possible anomalous valencies of $\mathrm{Ce}$ and $\mathrm{Eu}$. Nevertheless, an effect presumably related with the tetrad effect does not seem tangible for light REE span in Figs. 2, 3 and 4. Perhaps a reason for this might be that light REE are larger in ionic radii and more soluble than heavy REE. Also some attention might be paid to that the points for $\mathrm{La}, \mathrm{Nd}$ and $\mathrm{Sm}$ in Fig. 1 happen to fall on a 
straight line passing through them.

A general trend for $\mathrm{La}, \mathrm{Nd}$ and $\mathrm{Sm}$ obviously suggests a discontinuity at $\mathrm{Gd}$. To a much lesser extent, $\mathrm{Gd}$ discontinuities are recognized for chondrite-normalized REE patterns for deepsea cherts and siliceous microfossils (SHIMIZU and MASUDA, 1977). Very careful scrutiny of their data would enable us recognize that most of deep-sea siliceous materials reserve the hyperfine zigzag features with similar effect to that mentioned above. Findings reported here are expected to raise new intriguing problems not only with marine chemistry and geology but also with biological chemistry.

Acknowledgements-We thank Prof. S. OKABE, Tokai University, for his arrangements for participation of Mr. MANABU UENO and Mr. TATSUYA FUJITANI in navitation, which enabled them to collect the sea water sample for us. We are deeply grateful to Dr. E. ROALDSET, University of Oslo, for invaluable information about the tetrad effect.

\section{REFERENCES}

Goldberg, E. D., Koide, M., Schmitt, R. A., and SMITH, R. H. (1963) Rare-earth distributions in the marine environment. J. Geophys. Res. 68, 4209-4217.

Guillaumont, R., and DaVID, F. (1974) Fonctions thermodynamiques d'hydration et d'oxydo-reduction des iosn $\mathrm{M}^{3+}$ des lanthanides. Radiochem. Radio- anal. Lett. 17, 25-39.

HфGDahl, O. T., Melson, S., and Bowen, V. T. (1968) Neutron activation analysis of lanthanide elements in sea water. Advances in Chemistry Series No. 73, 308-325.

MASUDA, A. (1975) Abundances of monoisotopic REE, consistent with the Leedey chondrite values. Geochim. J. 9, 183-184.

Masuda, A., NAKamura, N., and TanaKa, T. (1973) Fine structures of mutually normalized rare-earth patterns of chondrites. Geochim. Cosmochim. Acta 37, 239-248.

NugENT, L. J. (1970) Theory of the tetrad effect in the lanthanide (III) and actinide (III) series. $J$. inorg. nucl. Chem. 32, 3485-3491.

Peppard, D. F., Mason, G. W., and LeWey, S. (1969) A tetrad effect in the liquid-liquid extraction ordering of lanthanides (III). J. inorg. nucl. Chem. 31, 2271-2272.

ShimizU, H., and MASUDA, A. (1977) Cerium in chert as an indication of marine environment of its formation. Nature 266, 346-348.

SIEKIERSKI, S. (1971) The shape of the lanthanide contraction as reflected in the changes of the unit cell volumes, lanthanide radius and the free energy of complex formation. J. inorg. nucl. Chem. 33, 377386.

SiEKIERSKI, S. and FIDELIS, I. (1972) The existence of regularities, tetrad or double-double effect in the changes in unit cell volumes of the compounds of the actinides in different oxidation states. J. inorg. nucl. Chem. 34, 2225-2231. 